\title{
Purge-and-trap Determination of Ammonia in Water Samples Using Needle-type Extraction Coupled with Gas Chromatography- Barrier Discharge Ionization Detection
}

\author{
Ikuo Ueta, ${ }^{* \dagger}$ Hiroto FujIKawa, ${ }^{*}$ Koji FujImura, ${ }^{* *}$ and Yoshihiro SAITo*** \\ *Department of Applied Chemistry, University of Yamanashi, 4-3-11 Takeda, Kofu 400-8511, Japan \\ **Shinwa Chemical Industries Ltd., 50-2 Kagekatsu-cho, Fushimi, Kyoto 612-8307, Japan \\ ***Department of Environmental and Life Sciences, Toyohashi University of Technology, 1-1 Hibarigaoka, \\ Tempaku-cho, Toyohashi 441-8580, Japan
}

\begin{abstract}
This manuscript describes the determination of ammonia $\left(\mathrm{NH}_{3}\right)$ in aqueous samples by purge-and-trap extraction using a needle-type extraction device with gas chromatography-barrier discharge ionization detector (GC-BID). $\mathrm{NH}_{3}$ was purged from the aqueous samples in basic conditions and then salted out with sodium chloride. Purged ammonia was trapped onto non-volatile carboxylic acid-coated macroporous terephthalic acid particles, which were contained within the needletype extraction device. The analyte $\left(\mathrm{NH}_{3}\right)$ was thermally desorbed by heating the extraction needle in the GC injection port, and detected by BID. After the optimization of both purge and extraction conditions, the linearity and sensitivity of the proposed method were evaluated. The limit of detection was found to be $2.0 \mathrm{mg} \mathrm{L}^{-1}$ at a headspace sampling volume of $100 \mathrm{~mL}$. The method applicability was confirmed by the determination of spiked $\mathrm{NH}_{3}$ in tap water and river water samples.
\end{abstract}

Keywords Ammonia, needle-type extraction, sample preconcentration, gas chromatography-barrier discharge ionization detection

(Received January 21, 2019; Accepted March 12, 2019; Advance Publication Released Online by J-STAGE March 22, 2019)

\section{Introduction}

Ammonia $\left(\mathrm{NH}_{3}\right)$ is a colorless gas with a pungent odor and high water solubility. Its aqueous form, the ammonium ion $\left(\mathrm{NH}_{4}^{+}\right)$, has a crucial role in both human and plant metabolism. ${ }^{1} \mathrm{NH}_{3}$ itself is widely used in the chemical industry as a source of nitrogen, and removal of $\mathrm{NH}_{3}$ from wastewater is also a critical step in water treatment. Accordingly, determination of $\mathrm{NH}_{3}$ in environmental water is key to the evaluation of water pollution. ${ }^{2}$

For the determination of $\mathrm{NH}_{3}$ in water samples, the Nessler and indophenol methods have been widely used due to its good sensitivity ${ }^{3}$ however, both have disadvantages. Firstly, the Nessler method requires the use of toxic mercury. The indophenol method can be adapted for the analysis of a range of sample types (water, soil, food, and biological materials), but its reaction conditions (reaction temperature, $\mathrm{pH}$, time, and reagent concentration) must be strictly controlled, and the method uses toxic phenol. Use of ammonium electrode is a simple, rapid and easy method. Several ammonium electrodes have been commercially available, and these electrodes have been used for the determination of ammonium ion in environmental ${ }^{4,5}$ and biological $^{6,7}$ samples. However, these methods are also sensitively affected by the sample temperature or coexisting ions. ${ }^{5,8}$ Another known method utilizes ion chromatography but

$\dagger$ To whom correspondence should be addressed.

E-mail: iueta@yamanashi.ac.jp generates inaccurate results when samples contain high concentrations of sodium. ${ }^{9}$ Sensitive determination of ammonia and ammonium ion has been reported by flow injection analysis (FIA), where less than $1 \mu \mathrm{g} \mathrm{L}^{-1}$ of ammonium ion in seawater samples was detected without interferences. ${ }^{10}$ A fully automated FIA for continuous monitoring of highly concentrated ammonium ion (up to $500 \mathrm{mg} \mathrm{L}^{-1}$ ) in industrial waste brine samples was also reported. ${ }^{11}$

Gas chromatography (GC) is the most suitable method for the determination of gaseous compounds. However, conventional detectors based on flame ionization detector, thermal conductivity detector, or mass spectrometry struggle to detect low-molecular-weight compounds, such as $\mathrm{NH}_{3}$, with sufficient sensitivity. This has led to the recent development of the barrier discharge detector (BID), which enables sensitive determination of all the gaseous compounds, except for helium and neon. ${ }^{12}$ BID-based analysis is therefore suitable for determination of $\mathrm{NH}_{3}$.

We have developed many needle-type extraction devices for the extraction of volatile organic compounds from both air ${ }^{13-15}$ and water samples. ${ }^{16-18}$ For the latter, a purge-and-trap (PT) method using an extraction needle has been employed, and this method has been successfully applied to the GC-BID analysis of formic acid and acetic acid. ${ }^{19,20}$ In PT extraction, because only volatile compounds are purged into headspace, the effect of coexisting ions could be eliminated. More recently, we have reported the determination of low-molecular-weight amines, including $\mathrm{NH}_{3}$ in gaseous samples by the extraction needle 


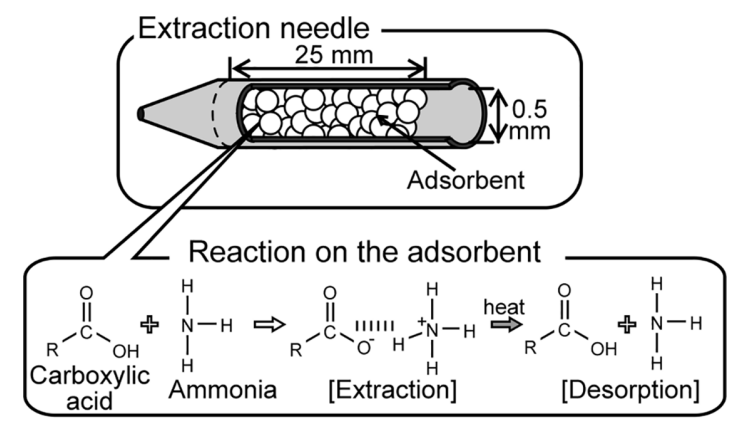

Fig. 1 Illustration of the extraction needle and reaction scheme in the extraction needle.

based GC-BID method. ${ }^{21}$ Carboxylic acid-coated macroporous terephthalic acid particles were used to trap volatile amines in gaseous samples via ionic adsorption. Subsequent thermal desorption of amine analytes from the adsorbent occurred in the GC injection port. Although this was an easy and sensitive method, extraction efficiencies were affected by the water content of the gaseous sample. However, $\mathrm{NH}_{3}$ was the exception, showing consistently high extraction efficiencies and sensitivities.

In this study, sample preparation using a needle-type extraction device followed by GC-BID analysis was applied to the determination of $\mathrm{NH}_{3}$ in water samples. After the optimization of several PT conditions, the method sensitivity, linearity, and repeatability were evaluated. Finally, the method applicability was confirmed by the determination of $\mathrm{NH}_{3}$ in tap water and river water samples spiked with this analyte.

\section{Experimental}

\section{Chemicals}

$\mathrm{NH}_{3}$ (28\% in water) was obtained from Tokyo Kasei Kogyo (Tokyo, Japan). Sodium chloride $(\mathrm{NaCl})$ was purchased from Kanto Chemical Co., Inc. (Tokyo, Japan). Sodium hydroxide $(\mathrm{NaOH})$ and ammonium chloride $\left(\mathrm{NH}_{4} \mathrm{Cl}\right)$ were obtained from Wako Pure Chemical Industries, Ltd. (Osaka, Japan).

\section{Needle-type extraction device}

The extraction needle was prepared by packing adsorbent particles into a stainless-steel needle having a tip hole of $8 \times 0.5 \mathrm{~mm}$ i.d. and $0.7 \mathrm{~mm}$ o.d. (Shinwa Chemical Industries, Kyoto, Japan). Non-volatile carboxylic acid-coated macroporous terephthalic acid particles (60/80 mesh, Shinwa Chemical Industries) were used as the adsorbent, with a sorbent packing length of $25 \mathrm{~mm}$. A small amount of Zylon ${ }^{\circledR}$ filament (Toyobo, Osaka, Japan) was also placed at each end of the packed section to fix the sorbent in place. The illustration of the extraction needle and the reaction between the carboxylic acid and ammonia are shown in Fig. 1. Ammonia is extracted on the adsorbent by ionic interaction, and it is desorbed as ammonia molecule by heating. The extraction needle can be reused more than 50 times.

\section{GC measurement}

A Shimadzu GC-2010 Plus capillary GC-BID instrument (Tracera, Shimadzu Corp., Kyoto, Japan) was used for all GC measurements. Separation was conducted using a CP-Volamine capillary column $(30 \mathrm{~m} \times 0.32 \mathrm{~mm}$, Agilent Technologies,

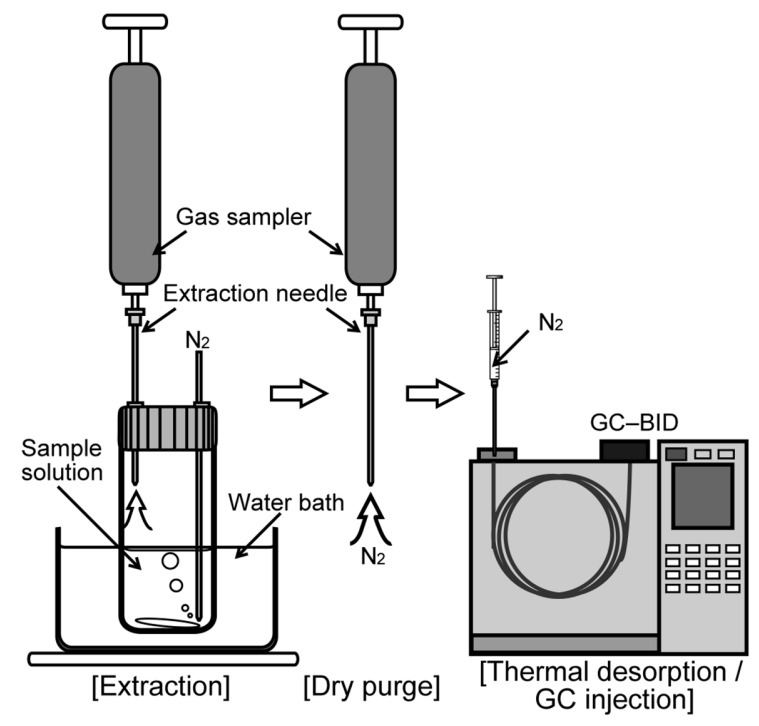

Fig. 2 Illustration of proposed PT-GC-BID analytical method.

Santa Clara, CA). Helium ( $>99.9999 \%$ ) was used as the carrier gas at a column head pressure of $150 \mathrm{kPa}$. The injection was performed using a split mode with a ratio of $10: 1$, and the column temperature was maintained at $35^{\circ} \mathrm{C}$. The injection port temperature and the detector temperature were set at 220 and $250^{\circ} \mathrm{C}$, respectively. A base-deactivated liner $(3.5 \mathrm{~mm}$ i.d., Restek Corp., PA, USA) was used as the inlet liner.

\section{Sampling and desorption methods}

A standard solution of $15 \mathrm{~mL}$ was prepared in a $30-\mathrm{mL}$ glass vial. Two silicon septa were attached in the plastic cap of the vial. After mixing with a magnetic stir bar, $5.4 \mathrm{~g}$ of $\mathrm{NaCl}$ (26.5\% in sample solution) and $0.1 \mathrm{~mL}$ of $1.5 \mathrm{~mol} \mathrm{~L}^{-1} \mathrm{NaOH}$ solution $\left(0.01 \mathrm{~mol} \mathrm{~L}^{-1}\right.$ in sample solution) were added to the solution, the vial was sealed, and the resulting solution was sonicated for $1 \mathrm{~min}$ at room temperature. The vial was then immersed in a $35^{\circ} \mathrm{C}$ water bath and stirred at $350 \mathrm{rpm}$ for $3 \mathrm{~min}$. The water bath was heated with a hot-plate stirrer. The extraction needle was then inserted into the vial through the septum, and a vacuum sampling device (Kitagawa AP-20, Komyo Rikagaku Kogyo, Tokyo, Japan) was connected to the extraction needle. A blank stainless-steel needle was inserted into the sample solution through another septum. This needle was connected to a gas sampling bag (Smart Bag PA, GL Sciences, Tokyo, Japan) filled with pure $\mathrm{N}_{2}$ gas. During the sampling of the headspace gas, the pure $\mathrm{N}_{2}$ gas was continuously supplied into the sample solution. The volume of headspace sample was $100 \mathrm{~mL}$ and was collected over approximately $8 \mathrm{~min}$. After the extraction, the extraction needle was attached to the vacuum sampling device again, and $200 \mathrm{~mL}$ of pure $\mathrm{N}_{2}$ gas was collected through the needle to remove excess water from the adsorbent. A scheme for the extraction and desorption procedures is given in Fig. 2.

The extraction needle was then attached to a gas tight syringe (1.0 mL volume), and $0.2 \mathrm{~mL}$ of $\mathrm{N}_{2}$ gas was collected from a gas sampling bag. Finally, the extraction needle was inserted into the heated $\mathrm{GC}$ injection port. The extracted $\mathrm{NH}_{3}$ was thermally desorbed from the adsorbent and introduced into the separation column. Desorption of the analytes by $\mathrm{N}_{2}$ gas was performed within $2 \mathrm{~s}$. 


\section{Real samples}

Two tap water samples were taken from two cities in Yamanashi prefecture, Japan. Two river water samples were taken from two different rivers in Yamanashi prefecture.

\section{Results and Discussion}

\section{Optimization of the method}

In PT analysis, condensation of water vapor on the adsorbent can occur. This water is vaporized in the heated GC injection port, generating a large amount of water vapor, which is vented from the GC via a vent line. However, analytes can co-vent with water vapor, and analyte response is also decreased by the water vapor captured by the adsorbent. Therefore, a dry-purge process has been widely applied to remove excess adsorbed water in PT analysis.

The optimal volume for sampling of dry nitrogen gas was investigated at a $0-300 \mathrm{~mL}$ range after PT extraction of $50 \mathrm{mg} \mathrm{L}^{-1}$ of standard solution. The headspace sampling volume (PT volume) was fixed at $100 \mathrm{~mL}$. The results showed that an analyte peak was not seen at a dry-purge volume of $0 \mathrm{~mL}$, and dry-purge volumes of 50 and $100 \mathrm{~mL}$ gave lower analytical repeatability, i.e., a smaller $\mathrm{NH}_{3}$ peak occurred with a bigger water peak. Better repeatability was obtained at drypurge volumes of 200 and $300 \mathrm{~mL}$, and a volume of $200 \mathrm{~mL}$ was used for the analysis.

The collection volume of headspace gas was investigated over a range of $50-300 \mathrm{~mL}$, with the dry-purge volume fixed at $200 \mathrm{~mL}$. The analyte peak area increased as the headspace sampling volume increased from 50 to $100 \mathrm{~mL}$, but not at a headspace sampling volume of $200 \mathrm{~mL}$. In our previous work, the peak area of $\mathrm{NH}_{3}$ in a gaseous sample linearly increased with sampling volumes of $50-300 \mathrm{~mL}^{21}$ The reason for the different results here could be the presence of water vapor in headspace sample: water vaper adsorption on the adsorbent during headspace sampling could prevent the adsorption of $\mathrm{NH}_{3}$. On the basis of this result, the headspace sampling volume was set at $100 \mathrm{~mL}$.

The effect of the addition of $\mathrm{NaOH}$ is shown in Fig. 3(A). The peak area of $\mathrm{NH}_{3}$ was significantly increased by adding $\mathrm{NaOH}$ into the sample solution because of the formation of more $\mathrm{NH}_{3}$ molecules at a higher $\mathrm{pH}$. The effect of the addition of $\mathrm{NaCl}$ is given in Fig. 3(B). The peak area was also increased with the $\mathrm{NaCl}$ addition because of salting-out of $\mathrm{NH}_{3}$ into the headspace. On the basis of these results, the $\mathrm{NaOH}$ and $\mathrm{NaCl}$ concentrations were fixed at $0.01 \mathrm{~mol} \mathrm{~L}^{-1}$ and $26 \%$ (saturated concentration), respectively.

The desorption ratio of the extracted $\mathrm{NH}_{3}$ was confirmed at desorption temperatures ranging from 200 to $250^{\circ} \mathrm{C}$. The results showed complete desorption of the analyte at investigated temperatures, therefore, the desorption temperature (i.e., injector temperature) was set at $220^{\circ} \mathrm{C}$.

\section{Evaluation of the method}

The limit of detection (LOD) was determined at a signal-tonoise ratio of 3.3, and the limit of quantification (LOQ) was determined at a ratio of 10 . The LOD and LOQ of the proposed method for a standard aqueous sample were 2.0 and $6.0 \mathrm{mg} \mathrm{L}^{-1}$, respectively. Slow sampling speed (e.g., $100 \mathrm{~mL}$ of head space sampling at $15 \mathrm{~min}$ ) showed more sensitive detection of the analyte. The upper LOQ was determined to be more than $1000 \mathrm{mg} \mathrm{L}^{-1}$. The relative standard deviation of the peak area was $12 \%$ in five consecutive analyses. The extraction and desorption recoveries did not decrease with consecutive use of
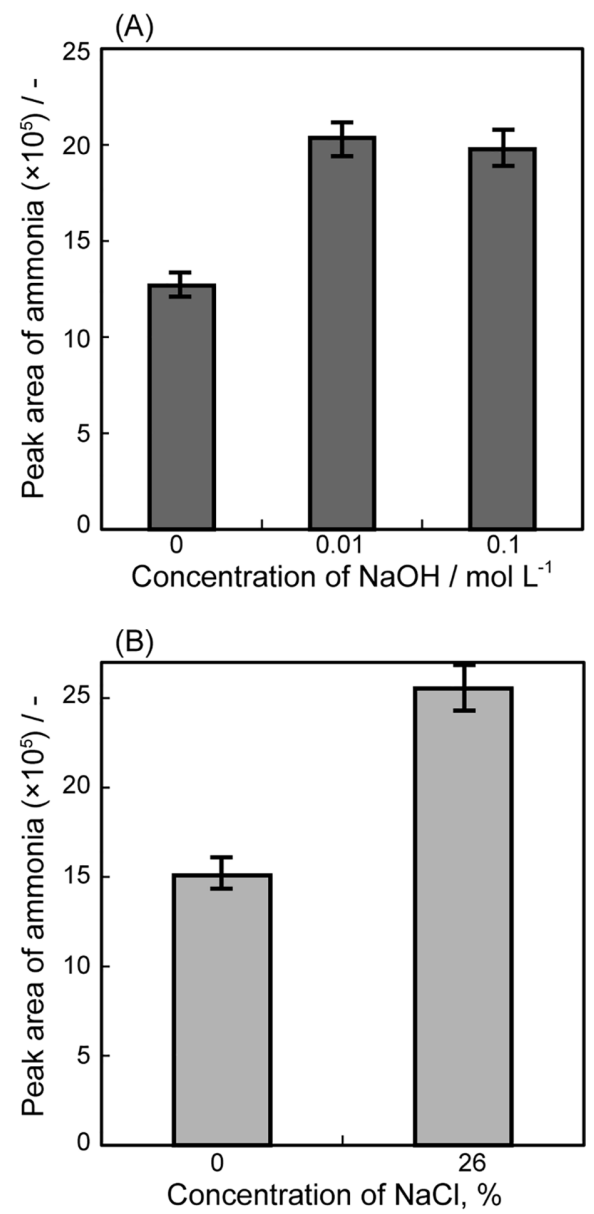

Fig. 3 Optimization of PT conditions. (A) Addition of $\mathrm{NaOH}$ and (B) addition of $\mathrm{NaCl}$. Concentration of $\mathrm{NH}_{3}: 50 \mathrm{mg} \mathrm{L}^{-1}$.

the extraction needle up to 50 times.

Quantification of $\mathrm{NH}_{4}{ }^{+}$as $\mathrm{NH}_{3}$ was investigated. The sample solution containing $50 \mathrm{mg} \mathrm{L}^{-1}$ of $\mathrm{NH}_{4}^{+}$was prepared using an $\mathrm{NH}_{4} \mathrm{Cl}$ aqueous solution. The recovery of $\mathrm{NH}_{4}{ }^{+}$was calculated by comparing the $\mathrm{NH}_{3}$ peak areas for $50 \mathrm{mg} \mathrm{L}^{-1}$ of $\mathrm{NH}_{4}^{+}$ containing solution and $\mathrm{NH}_{3}$ solution. The recovery of $\mathrm{NH}_{4}{ }^{+}$ was $97 \pm 6 \%(n=5)$, and quantitative recovery of $\mathrm{NH}_{4}{ }^{+}$was thus confirmed.

\section{Real sample analysis}

The method applicability was confirmed by the determination of aqueous samples spiked with $\mathrm{NH}_{3}$. Two tap water samples (two cities in Yamanashi prefecture) and two river water samples (Kofu, Yamanashi) were determined. The concentration of $\mathrm{NH}_{4}{ }^{+}$ in river water is an important indicator for eutrophication. In this study, $\mathrm{NH}_{3}$ was not detected $\left(<2.0 \mathrm{mg} \mathrm{L}^{-1}\right)$ from the investigated tap water and river water samples. The LOQ obtained was not sufficient for the determination of trace ammonia included in environmental water samples, and further improvement is needed to analysis trace ammonia. The recovery of spiked $\mathrm{NH}_{3}$ from $\mathrm{NH}_{3}$-spiked samples was evaluated by comparing the peak areas of spiked $\mathrm{NH}_{3}$ with those of pure water and real aqueous samples. The extraction recoveries from spiked samples are given in Table 1. As shown in the table, spiked $\mathrm{NH}_{3}$ was successfully recovered from both tap water and river water samples. Figure 4 showed a typical chromatogram for the determination of spiked $\mathrm{NH}_{3}$ in river water samples. 
Table 1 Recoveries of $\mathrm{NH}_{3}$ from real samples.

\begin{tabular}{cc}
\hline Sample & Recovery, \% \\
\hline Tap water (A) & $105 \pm 8$ \\
Tap water (B) & $102 \pm 5$ \\
River water (A) & $105 \pm 7$ \\
River water (B) & $100 \pm 6$ \\
\hline
\end{tabular}

Concentration of $\mathrm{NH}_{3}: 20 \mathrm{mg} \mathrm{L}^{-1}$.

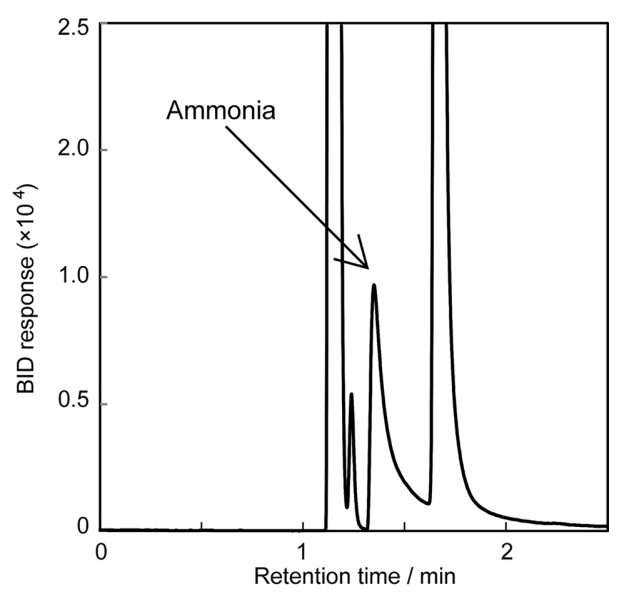

Fig. 4 Typical chromatogram for the determination of spiked $\mathrm{NH}_{3}$ in river water samples. Concentration of $\mathrm{NH}_{3}: 20 \mathrm{mg} \mathrm{L}^{-1}$.

The chromatogram was almost the same as that of a standard solution (spiked in pure water), where interference peaks were not observed. Although the sensitivity of the proposed method is the same as that of the conventional analytical method, aqueous $\mathrm{NH}_{3}$ (i.e., $\mathrm{NH}_{4}^{+}$) could be quantitatively and selectively determined with simple and rapid sample preparation.

\section{Conclusions}

In this study, PT extraction with a needle-type extraction device and GC-BID analysis was successfully applied to simple and rapid determination of aqueous $\mathrm{NH}_{3}$. The LOD of the method was $2.0 \mathrm{mg} \mathrm{L}^{-1}$, and analytical time, including PT extraction and dry purge, was less than 30 min. Because $\mathrm{NH}_{3}$ was extracted using a PT method, the method was unaffected by contaminants that are typically present in tap water or river water. In addition, because the PT temperature was maintained at a constant temperature, analytical temperature such as temperature of sample solution or room temperature, did not affect the quantitative results in the proposed method. The proposed method could be useful for the determination of aqueous $\mathrm{NH}_{3}$ in the evaluation of $\mathrm{NH}_{3}$ decomposition with a catalyst. Further sensitivity improvement is required, with which the method could also be suitable for the determination of $\mathrm{NH}_{4}{ }^{+}$for the evaluation of eutrophication of environmental water samples. The analytical method using a needle-type extraction device and a universal detector of BID does not require a toxic reagent, and the method would be suitable for the detection of low-molecular weight organic compounds.

\section{Acknowledgements}

This research was financially supported by the Shimadzu Science Foundation and the Japan Society for the Promotion of Science (JSPS) KAKENHI (Grant Number 18K05169).

\section{References}

1. "Ammonia in Drinking-Water", in "Guidelines for DrinkingWater Quality”, 2nd ed., 1996, World Health Organization, Genova.

2. Q. N. Ata, K. Aygun, H. Okur, and A. Kanca, Int. J. Environ. Sci. Technol., 2016, 13, 2459.

3. P. L. Dearle, Analyst, 1984, 109, 549.

4. A. G. A. Merks, Neth. J. Sea Res., 1975, 9, 371.

5. Y. Kan, C. Han, Y. Ye, X. Zhang, Y. Huang, L. Xing, Y. Zhou, and H. Qin, Int. J. Electrochem. Sci., 2016, 11, 9928.

6. J. Georges, Clin. Chem., 1979, 25, 1888.

7. J. R. Huizenga, A. Tangerman, and C. H. Gips, Ann. Clin. Biochem., 1994, 31, 529.

8. Ammonia Electrode 5002A Instruction Manual, HORIBA, 2008.

9. Y. Huang, S. F. Mou, and J. M. Riviello, J. Chromatogr. A, 2000, 868, 209.

10. K. Fukui, S. Ohno, K. Higuchi, N. Teshima, and T. Sakai, Bunseki Kagaku, 2007, 56, 757.

11. K. Higuchi, K. Takahashi, N. Teshima, and T. Sakai, Bunseki Kagaku, 2008, 57, 531.

12. R. Pascale, M. Caivano, A. Buchicchio, I. M. Mancini, G. Bianco, and D. Caniania, J. Chromatogr. A, 2017, 1480, 62.

13. I. Ueta, A. Mizuguchi, K. Fujimura, S. Kawakubo, and Y. Saito, Anal. Chim. Acta, 2012, 746, 77.

14. I. Ueta and Y. Saito, Anal. Sci., 2014, 30, 105.

15. I. Ueta, E. L. Samsudin, A. Mizuguchi, H. Takeuchi, T. Shinki, S. Kawakubo, and Y. Saito, J. Pharm. Biomed. Anal., 2014, 88, 423.

16. I. Ueta, N. A. Razak, A. Mizuguchi, S. Kawakubo, Y. Saito, and K. Jinno, J. Chromatogr. A, 2013, 1317, 211.

17. I. Ueta, T. Mitsumori, S. Kawakubo, and Y. Saito, Anal. Sci., 2014, 30, 979.

18. I. Ueta, T. Mitsumori, Y. Suzuki, S. Kawakubo, and Y Saito, J. Chromatogr. A, 2015, 1397, 27.

19. I. Ueta, Y. Nakamura, K. Fujimura, S. Kawakubo, and Y. Saito, Chromatographia, 2017, 80, 151.

20. I. Ueta, Y. Nakamura, S. Kawakubo, and Y. Saito, Anal. Sci., 2018, 34, 201.

21. I. Ueta, Y. Nakamura, H. Fujikawa, K. Fujimura, and Y. Saito, Chromatographia, 2019, 82, 317. 